\title{
Los sentidos de sensación y percepción del verbo agarrar
}

\section{The sense of sensation and perception of the verb agarrar (grab)}

\author{
Verónica Jenny Lazo García \\ Universidad Nacional Mayor de San Marcos \\ veronica.lazo@unmsm.edu.pe
}

\section{Resumen}

En el presente artículo, se describe los sentidos mentales del verbo polisémico agarrar y las estructuras sintácticas resultantes del perfilamiento de tales sentidos. El estudio es una aproximación a la red construccional de los usos lingüísticos en los que los hablantes describen diversos eventos con esta categoría compleja de sentidos, entre los cuales se establecen relaciones de semejanza de familia. Plantearemos, por tanto, que el perfilamiento de los roles semánticos determina la esquematización sintáctica, evidenciando con ello relaciones entre semántica y sintaxis. El análisis propuesto es tomado del enfoque de la Gramática de Construcciones, dentro de la lingüística cognitiva.

Palabras claves: Semejanza de familia, clases verbales, roles semánticos, relato natural, gramática de construcciones

\begin{abstract}
In the present article, we describe the mental senses of the polisemic verb "agarrar" and syntactic structures resulting from the profiling of such senses. The study is an approximation to the constructional network of linguistic uses in which speakers describe various events with this complex category of meanings, among which family-like relationships are established. We will propose that the profiling of the semantic roles determines the syntactic schematization, thus evidencing relations between semantics and syntax. The proposed analysis is taken from the Constructions Grammar approach, within cognitive linguistics.
\end{abstract}

Keywords: Family Resemblance, Verbal Macro Classes, Semantic Roles, Natural Narrative, Construction Grammar 


\section{Introducción}

En el habla espontánea, prima la creatividad de los hablantes, quienes emplean el código no solo para representar la realidad, sino para transformarla y proyectar su subjetividad con sus interlocutores. Por ello, en la lengua cotidiana las palabras son principalmente polisémicas, como ocurre con el verbo agarrar. Así, por ejemplo, en (a) Les agarré cariño a las arañas, (b) Mi cel no agarra señal y (c) Entonces agarra y le dice: «iY, vives por acá?», agarrar varía semánticamente (y también de forma sintáctica) de acuerdo al contexto, mediante procesos metafóricos y metonímicos, evidenciando el uso de formas y funciones con diferentes grados de prototipicidad entre los sentidos, y no solo con el prototipo asir (sentido material de control).

En el enunciado (a), el sentido es similar a [empezar a] sentir, y la construcción es ditransitiva; en (b), el sentido es muy similar al que describe captar y la estructura es transitiva; asimismo el enunciado (c) el sentido es similar al que describe reaccionar, y presenta una construcción intransitiva y está conectada a un verbo, cumpliendo una función similar a la de un modal. El verbo agarrar no tendría, pues, un solo sentido, ni todos tendrían que ser de control material: más que del sentido del verbo, se tendría que hablar del sentido de las construcciones convencionalizadas por los hablantes, quienes compartirían marcos o modelos cognitivos (Van Dijk, 1992; Fillmore, 1975, 1982).

El objetivo de esta investigación es establecer la red de esquemas construccionales del verbo agarrar, dentro del dominio mental, y explicar la variación semántico-sintáctica. Por ello, y de acuerdo con la gramática de construcciones, intentaremos explicar cómo la categorización léxico-sintáctica incide en la esquematización de las construcciones donde aparece la categoría polisémica agarrar, en el dominio mental. Defenderemos la idea de que las diferentes construcciones de agarrar son producto de la categorización léxico-sintáctica fijada por la experiencia, la cual consiste en los sentidos contextuales del verbo y los sentidos de las construcciones, que expresan la manera de conceptualizar los eventos por los hablantes, al perfilar ciertos participantes, de manera explícita o implícita.

Los verbos de la macroclase mental describen una entidad dotada de vida psíquica que mantiene o experimenta algún tipo de estado, cambio de estado o actividad interior perceptiva, sensitiva y/o cognitiva. Entre los diversos usos de agarrar los hablantes han fijado, además de los sentidos de control material, sentidos de percepción, que consisten en obtener información por medio 
de algún órgano sensorial, los cuales se asociarían con el prototipo asir por medio de coger (asir y llevar a un lugar) y recoger (asir de un lugar). Los sentidos de sensación, en los que una entidad se ve afectada psíquicamente por algo, se asocian con asir por medio de dominar, ejercer control sobre otro. La figura 1 muestra la asociación del sentido de control con los sentidos de percepción y sensación dentro de la clase mental.

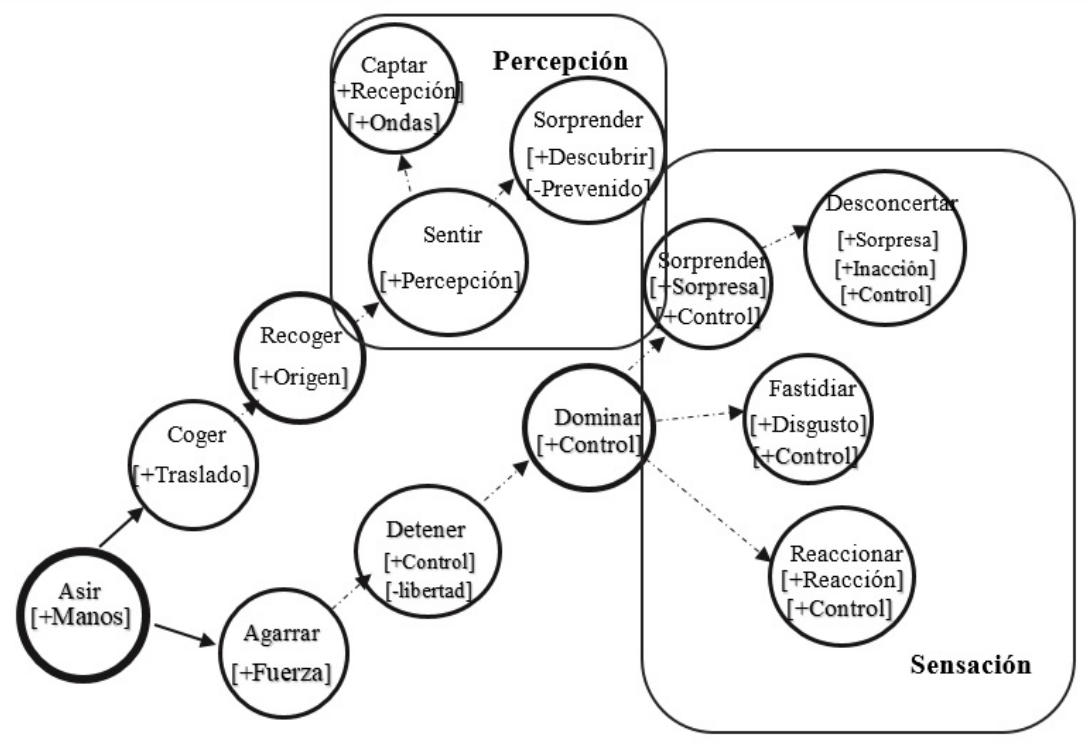

Figura 1: Asociaciones de los sentidos de control y mental del verbo agarrar

\section{Clases verbales}

Los verbos se clasifican conceptualmente - según el proyecto Adesse (Base de Datos de Verbos, Alternancias de Diátesis y Esquemas Sintáctico-Semánticos del Español $)^{1}$, que sigue un enfoque cognitivo de los significados de los verbos y sus esquemas - en seis macroclases, las cuales incluyen clases específicas, y en ellas participan argumentos variados. Esas seis macroclases son: mentales, relacionales, verbales, existenciales, de modulación y materiales.

1.1. Verbos de control: El control es un proceso que suele consistir en la limitación por parte de la primera entidad de la libertad de movimientos de la segunda o en la capacidad o disposición de la primera para usar a la segunda mediante algún tipo de contacto físico. Los argumentos prototípicos se enuncian 
de la siguiente forma: Una entidad (A1) toma el control de otra (A2). La entidad A1 es el controlador y la otra entidad A2 es el controlado. Ejemplo:

(1) Cuando ya estoy agobiada de tanto trabajo, ya me están volviendo loca, agarro mi iPod, me voy a correr. (E78-PT Entre tú y yo 5/11/11)

1.2. Verbos de percepción: Una entidad dotada de órganos sensoriales, perceptor, (A1) tiene contacto objetivo a través de estos con alguna realidad del entorno u obtiene alguna información de este, percibido, (A2). En estos casos también puede aparecer un iniciador de la percepción. Los sentidos de percepción asociados con agarrar son sentir, sorprender y captar.

\section{A. Sentir}

El sentido de este verbo es percibir, notar algo. Sus argumentos son percibido, perceptor y meta. En algunos contextos, los hablantes prefieren usar el verbo agarrar, en vez del verbo sentir, porque tiene un matiz semántico: 'empezar a sentir'; además, es un verbo con frecuencia material, y resulta más cómodo para el hablante, como presentamos a continuación:

(2) Parece que también a mí me agarró tirria ya para siempre. (E59-TE, Bryce Echenique Alfredo, El huerto de mi amada: 2002, Corde)

Sentido: El narrador cuenta cómo un personaje empezó a sentir tirria hacia él. Roles participantes: meta (a mí me), perceptor (3.a p. sing.), percibido (tirria) Esquema sintáctico resultante: S OI V OD (Construcción activa)

Al parecer esta elección inconsciente por parte del hablante de la construcción a mí me agarró tirria en vez de empezó a sentir tirria hacia mí, radica en que el sentido de la construcción está más fijada en la mente del hablante por la experiencia, en tanto que la construcción con sentir aparece en contextos formales, no cotidianos. Sentir está fuera del alcance cognitivo, por eso, oímos y decimos cotidianamente tengo frío, en vez de siento frío, donde la diferencia también se ubica en el modelo cognitivo de posesión en los casos de sustantivos escuetos (Garachana y Hilferty, 2005).

\section{B. Sorprender}

El sentido de este verbo es 'descubrir algo o a alguien normalmente desprevenido'. Sus argumentos son perceptor y percibido. Ahora, los hablantes preferirían describir el evento con agarrar, pues añaden el matiz de control en la situación. 
(3) El cablegrama estuvo circulando por todo el mundo, hasta que me agarró en Pativilca. (E21-TE, Corrales, Juan Apapucio: Crónicas políti codoméstico-taurinas, Perú, 1908, Corde)

Sentido: El narrador cuenta cómo el cablegrama lo descubrió y controló de forma sorpresiva.

Roles participantes: perceptor (el cablegrama), percibido (me)

Esquema sintáctico resultante: S OD V (Construcción activa)

En (3) se instancia la metáfora LAS COSAS SON PERCEPTORES. En (4), el perceptor es humano, por lo que no se instancia esa misma metáfora.

(3) Los agarraron en pleno juicio oral: pareja tuvo sexo en un baño de Tribunales. (E138- RS-Diario registrado, Mar del Plata, 7/17/16)

Sentido: El narrador cuenta cómo 3.a p. pl descubrieron a ellos de forma sorpresiva.

Roles participantes: perceptor (3.a p. pl.), percibido (los)

Esquema sintáctico resultante: S OD V (Construcción activa)

\section{Captar}

No consideramos que sea un verbo de control, sino de percepción, ya que su sentido asociado con agarrar es recibir ondas, imágenes o emisiones radiodifundidas. Sus argumentos son perceptor y percibido. Al perfilarse el percibido, se instancia la metáfora LOS OBJETOS SON PERCEPTORES (como en 2).

(4) Mi móvil no agarra señal móvil, he intentado de todo pero no logro solucionar. (E103- RS Movildualsim.com 10/09/15)

Sentido: El narrador cuenta que su móvil no capta señal.

Roles participantes: perceptor (mi móvil), percibido (la señal móvil)

Esquema sintáctico resultante: S V OD (Construcción activa)

1.3. Verbos de sensación: Una entidad capacitada para tener sentimientos o emociones, experimentador (A1), se ve afectada psíquicamente por algo o muestra una determinada disposición subjetiva hacia algo, estímulo (A2). Ejemplos: desconcertar, fastidiar, reaccionar... 


\section{A. Desconcertar}

El sentido de agarrar asociado con desconcertar es 'sorprender a alguien dejándolo sin saber qué pasa o qué hacer, controlándolo'. Sus argumentos son experimentador y estímulo.

(5) - Doctor, comprenda usted...

- No, Martín, es usted el que tiene que comprender que si Inés no acepta todas las consecuencias e incomodidades del tratamiento, no merece ser su compañera. Ahí sí que me agarró. Era una verdad como una catedral. Cuánto hubiera dado yo por soltar verdades de ese tamaño. (E53-TE, Bryce Echenique, Alfredo: La vida exagerada de Martín Romaña, 1995, Corde)

Sentido: El narrador cuenta que una verdad lo desconcertó, lo controló.

Roles participantes: experimentador (me), estímulo (una verdad)

Esquema sintáctico resultante: S OD V (Construcción activa)

\section{B. Fastidiar}

El sentido de fastidiar asociado con la categoría agarrar es 'disgustar a alguien produciendo molestia'. Sus argumentos son experimentador y estímulo, como mostramos a continuación:

(6) ¿A ti no te agarró alguien de puerquito en la escuela, chata? (E31TE- Fuentes, Carlos: La región más transparente-MÉXICO, 1958, Corde)

Sentido: El hablante pregunta si alguien la fastidió en la escuela.

Roles participantes: experimentador (te), estímulo (3.a p. sing.), manera (de puerquito)

Esquema sintáctico resultante: S OD V S(de) (Construcción activa)

\section{Sorprender}

El sentido de sorprender, relacionado con los usos de agarrar en esta sección, es que un estímulo causa sorpresa a alguien y lo controla. Así se diferencia del sentido de sorprender en el dominio de percepción, el cual indica que un perceptor descubre a alguien desprevenido (percibido). Los argumentos del sentido de sensación son experimentador y estímulo.

(7) En la subida los agarró una tempestad de aire. Avanzaron penosamente. (E40-TE- Scorza, Manuel: La tumba del relámpago, 1988: Corde) 
Sentido: El narrador cuenta que un fenómeno atmosférico los sorprendió. Roles participantes: experimentador (los), estímulo (tempestad de aire) Esquema sintáctico resultante: S OD V (Construcción activa)

\section{Reaccionar}

El sentido de reaccionar asociado con la categoría agarrar es responder a un estímulo determinado, por lo tanto los argumentos son experimentador y estímulo. Este sentido es muy importante, puesto que en la superestructura de los relatos, la reacción es la respuesta a la acción sorpresiva, problemática que se cuenta de un personaje. En los siguientes ejemplos, aparece dentro de una construcción compleja coordinada con un verbo.

(8) Una vez, este, conversé con una) un pata, y... Teina estaba que le llamaba la atención a Joaquín, y yo agarré, y yo agarré, le digo: “Oy, déjalo al bebe, ¡qué pasa!"- le dije, ¿no? (E67-CE-4-2009-M)

Sentido: El narrador relata cómo reaccionó ante una acción.

Roles participantes: experimentador (1.a p. sing.), estímulo (Teina estaba que le llamaba la atención a Joaquín)

Esquema sintáctico resultante: Cláusula 1 (ACCIÓN/ EST) (MD) agarrar (MD) Cláusula 2 (RESOLUCIÓN)

(9) No te metas- me dice. Mil veces, aunque sea, salte si no quieres ver que le griten a tu hijo $<$ mejor agarra, retírate $>$ porque le quitas autori dad... (E68-CE-4-2009-F)

Sentido: La interlocutora interrumpe el discurso expresando por anticipado una sugerencia frente a la acción penosa.

Roles participantes: experimentador (2.a p. sing.), estímulo (que le griten a tu hijo)

Esquema sintáctico resultante: Cláusula 1 (ACCIÓN/ EST) (MD) agarrar (MD) Cláusula 2 (RESOLUCIÓN)

\section{Metodología}

La muestra está constituida por enunciados sincrónicos de diversas variedades lingüísticas (en redes sociales, entrevistas, conversaciones espontáneas), así como enunciados de los siglos XVI-XXI, registrados en el corpus diacrónico del español $\left(\operatorname{Corde}^{2}\right)$. Para el análisis, tomamos como referencia los esquemas cons- 
truccionales de la Base de Datos Adesse (Base de Datos de Verbos, Alternancias de Diátesis y Esquemas Sintáctico-Semánticos del Español). En el marco de referencia se maneja conceptos cognitivos de la gramática de construcciones, así como conceptos de las teorías del significado dentro de la lingüística cognitiva, las clases de verbos y la teoría del relato natural.

\section{Resultados}

\subsection{Esquemas sintácticos resultantes de la macroclase mental}

Los esquemas resultantes de las asociaciones con los sentidos de esta macroclase son construcciones transitivas activas, en las cuales el perceptor y el estímulo se asocian con el sujeto; el objeto percibido y el experimentador, con el objeto directo; la meta, con el objeto indirecto, y la manera, con el suplemento. En el caso del sentido de reaccionar, el estímulo es el enunciado anterior, y la resolución, inicia con un marcador consecutivo + el verbo agarrar + marcador y + verbo de acción. La tabla 1 contiene la relación léxico-sintáctica en los esquemas sintácticos asociados con los sentidos de percepción y sensación en la macroclase mental.

\begin{tabular}{|c|c|c|c|c|c|}
\hline CONSTRUCCIONES & & SENTIDO DE & \multicolumn{3}{|c|}{ ROLES PARTICIPANTES } \\
\hline \multirow[t]{7}{*}{ Activas } & \multirow[t]{3}{*}{ Percepción } & Sentir & $\begin{array}{l}\text { PCTR } \\
\mathrm{S}\end{array}$ & $\begin{array}{l}\text { PCDO } \\
\text { OD }\end{array}$ & $\begin{array}{l}\text { META } \\
\text { OI }\end{array}$ \\
\hline & & Sorprender & $\begin{array}{l}\text { PCTR } \\
\text { S }\end{array}$ & $\begin{array}{l}\text { PCDO } \\
\text { OD }\end{array}$ & \\
\hline & & Captar & $\begin{array}{l}\text { PCTR } \\
\mathrm{S}\end{array}$ & $\begin{array}{l}\text { PCDO } \\
\text { OD }\end{array}$ & \\
\hline & \multirow{4}{*}{ Sensación } & Sorprender & $\begin{array}{l}\text { EST } \\
\text { S }\end{array}$ & $\begin{array}{l}\text { EXP } \\
\text { OD }\end{array}$ & \\
\hline & & Desconcertar & $\begin{array}{l}\text { EST } \\
\text { S }\end{array}$ & $\begin{array}{l}\text { EXP } \\
\text { OD }\end{array}$ & \\
\hline & & Fastidiar & $\begin{array}{l}\text { EST } \\
\text { S }\end{array}$ & $\begin{array}{l}\text { EXP } \\
\text { OD }\end{array}$ & $\begin{array}{l}\text { MAN } \\
\text { S (de) }\end{array}$ \\
\hline & & Reaccionar & \multicolumn{3}{|c|}{$\begin{array}{l}\text { EXP } \\
\text { S } \\
\text { Cláusula } 1_{\text {(Acción/ EST) }}(\mathrm{MD}) \text { agarrar (MD) } \\
\text { Cláusula } 2_{\text {(REsolución) }}\end{array}$} \\
\hline
\end{tabular}

Tabla 1: Esquematización de los sentidos de la macroclase mental del verbo agarrar

La figura 2 muestra la esquematización a partir de la categorización asociada con la macroclase mental. 


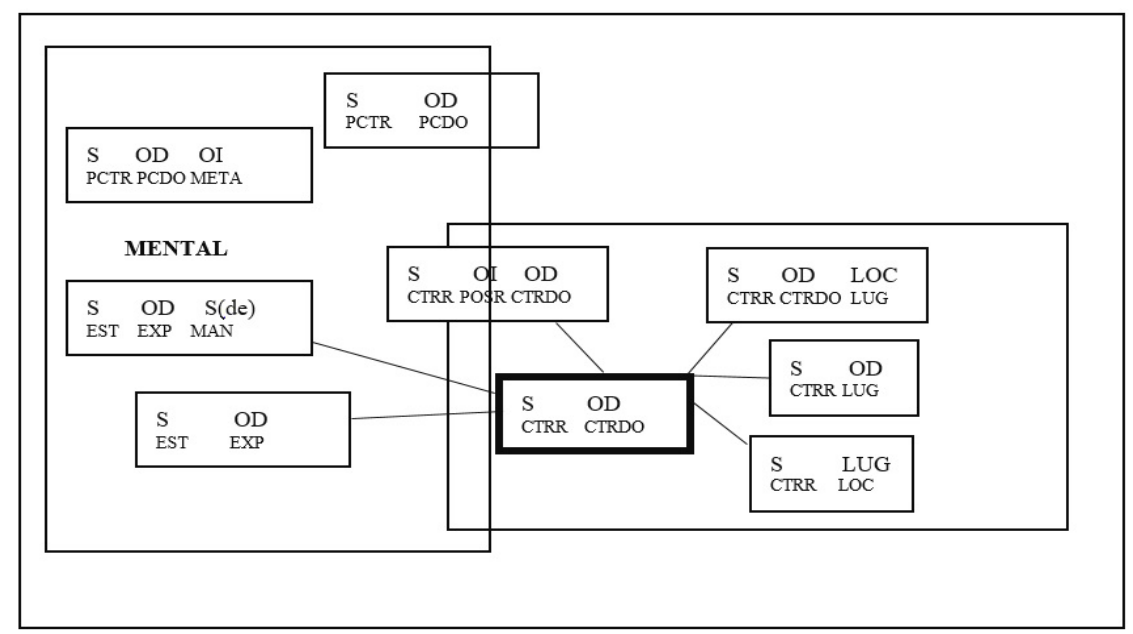

Figura. 2: Esquematización de la macroclase Mental asociada con el verbo agarrar

\subsection{Frecuencia de uso}

La figura 3 muestra las frecuencias de los sentidos de percepción y sensación dentro de esta macroclase. El sentido de percepción de sorprender es registrado en el siglo XVIII, mientras que en el siglo XX, sorprender (sensación), fastidiar y desconcertar; por último en el siglo XXI se registra el uso de sentir, captar y reaccionar.

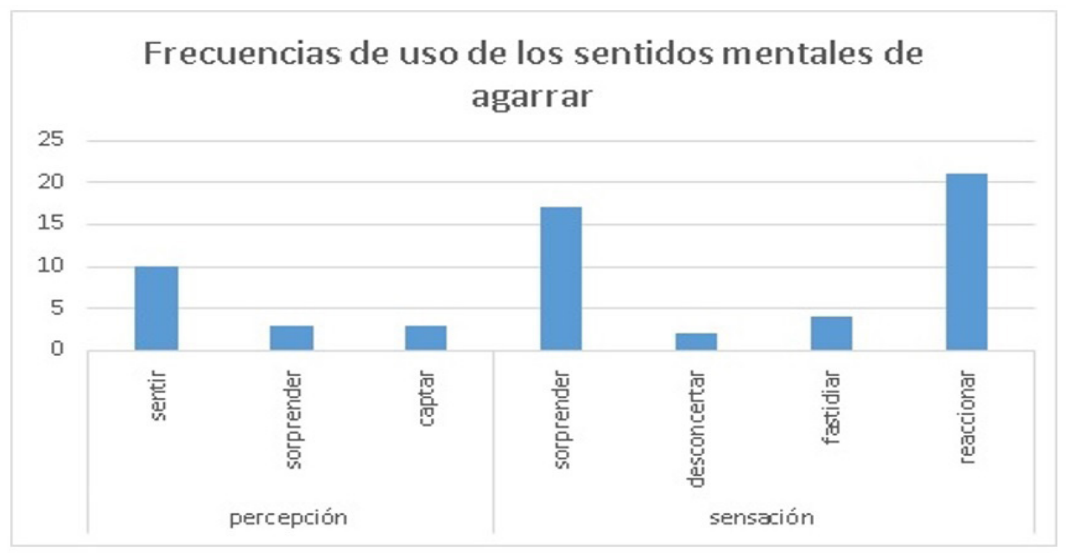

Fig. 3: Frecuencias de uso de los sentidos de agarrar asociados con la macroclase Mental 


\subsection{Procesos metafóricos y metonímicos}

Perfilamiento del objeto percibido

Al perfilar el objeto percibido, se instancia la metáfora LAS PERSONAS SON LUGARES.

$$
\begin{gathered}
\text { A mí me agarró [tirria]. } \\
\text { Meta percibido } \\
\downarrow \\
\text { Yo soy UN LUGAR }
\end{gathered}
$$

Perfilamiento del perceptor

Al perfilar el perceptor, se instancia la metáfora LOS ESTADOS Y SENSACIONES SON OBJETOS CONCRETOS.

[1.a p. sing.] Le agarré una cólera a mi pareja

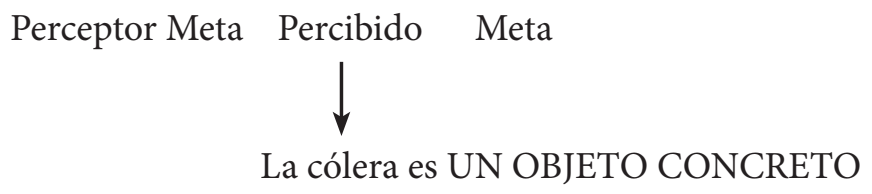

Proceso metonímico agarrar por reaccionar

La construcción $\{(\mathrm{MD})$ agarrar $+(\mathrm{MD})+$ verbo $\}$ por sí misma es significativa. A través de la categorización del sentido mental de reaccionar, lo cual permite categorizar a un solo argumento: el experimentador. La categorización se establece por la frecuencia de uso, la cual crea una rutina que sirve de base para su interpretación; y es producto de la metonimia, debido a que reaccionar forma parte del dominio de control, pero en ella se resalta el controlar la situación y no un objeto por contacto físico, sino la sensación frente a los hechos vividos y relatados en el discurso. La figura 4 ilustra el proceso metonímico involucrado. 


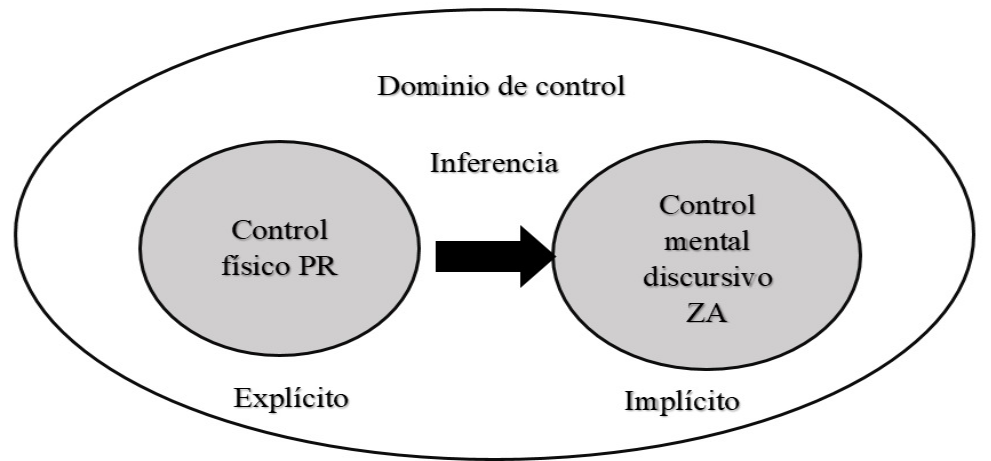

Fig. 4: Estructura interna de la metonimia EL CONTROL FÍSICO POR EL CONTROL DISCURSIVO

La función textual de la construcción $\{(\mathrm{MD})+$ agarrar $+(\mathrm{MD})+$ verbo $\}$ es señalar la resolución del relato, ya que frente a la complicación, las personas actúan o reaccionan. Los resultados de esas acciones pueden ser positivos o negativos, el conjunto de estas acciones se denomina RESOLUCIÓN. Lo interesante es la clase de verbos coordinados con agarrar, como decir, irse, retirarse, venir. Se entiende que solucionar un problema puede basarse en la palabra o el escape.

\section{Discusión}

Como se ha podido apreciar, la categoría agarrar es una red de sentidos, entre los cuales se establecen distintas relaciones, y resultan en esquemas sintácticos variados fijados por el uso y la experiencia, de acuerdo a las características sociales, geográficas de los hablantes. La forma como se conciben los eventos desencadena diferencias sintácticas: existen modelos cognitivos que motivan preferencias entre los hablantes. Además, los diferentes tipos de construcciones generan cambios en la estructura semántica del agarrar. Queda comprobada, entonces, la flexibilidad sintáctica de los verbos, propuesta por García Miguel $(2005)^{3}$, es decir, pueden encontrarse en más de un esquema, debido a que el contexto permite el perfilamiento de ciertos participantes.

Pese a esta flexibilidad sintáctica, la frecuencia de uso fija en la memoria de los hablantes estructuras prototípicas que sirven de modelo a otros sentidos. El verbo agarrar es prototípicamente transitivo, pero eso no significa que sean anómalos los enunciados intransitivos, solo son menos frecuentes, en ciertas variedades, pero cumplen una función específica en la comunicación. 
Por su parte, la aparición de funciones sintácticas como suplementos, objetos indirectos en esquemas considerados básicamente transitivos, del verbo agarrar, corroboran la idea de que en la gramática, la semántica y la sintaxis no son dominios discretos, debido a que como fue propuesto por Ignacio Pereira (2013) la diferencia semántica entre construcciones se debe al perfilamiento de los roles argumentales.

Los esquemas sintácticos son correspondencias específicas entre funciones sintácticas y roles semánticos. García-Miguel (2005) asegura que los grados de esquematización prueban la relación entre léxico y sintaxis:

Los esquemas sintácticos son inherentes a las expresiones concretas que los realizan y en el proceso de esquematización no hay límites claros entre el dominio del léxico y el de la sintaxis, sino un continuo en el que intervienen diferentes grados y caminos de esquematización.

(García-Miguel, 2005, p. 177)

De este modo, la categorización o la conformación de la estructura lingüística es posible por la alta frecuencia de uso ${ }^{4}$ (García-Miguel, 2005 y Calzado, 2015). Por último, la construcción $\{(\mathrm{MD})$ agarrar + $(\mathrm{MD})+$ verbo $\}$ resulta de la esquematización del sentido de reaccionar. Debido a que en la categorización de este sentido solo se perfila un rol participante, en la sintaxis el resultado es una estructura intransitiva. Esto es posible por un proceso metonímico del control físico por el control discursivo.

\section{Conclusiones}

1. La forma como se conciben los eventos desencadenan diferencias sintácticas; así como los diferentes tipos de construcciones generan, explícita o implícitamente, cambios semánticos en la estructura semántica del verbo. Los esquemas gramaticales contienen imágenes convencionalizadas; la gramática es en sí misma significativa.

2. Los sentidos del verbo agarrar son categorías difusas que se asocian con otros dominios cognitivos y que relacionan, mediante cadenas de significados, diversos ámbitos de conocimiento como la macroclase verbal mental (asociado con 7 sentidos). Las redes conceptuales emulan las relaciones jerárquicas de semejanza de familia.

3. Debido a que la categoría agarrar no tiene un solo sentido, sus roles participantes no siempre son el controlador y el objeto controlado. Al emplearse en 
construcciones específicas, el verbo perfila diferentes roles, que resultan en esquemas sintácticos variados. Estos roles se organizan en dominios que corresponden con las clases verbales, entre las que existen vínculos conceptuales como la metonimia.

4. El sujeto no siempre es un controlador humano, puede ser perceptor (sentido de percepción) o un estímulo (sentido de sensación). Asimismo, el objeto directo no solo expresa el significado del controlado, sino otras funciones, como el percibido o el experimentador.

5. Pese a la flexibilidad sintáctica, la frecuencia de uso fija estructuras más prototípicas que sirven de modelo a otros verbos. Esas estructuras más frecuentes son las transitivas en las que se perfilan dos participantes: el agente y el paciente, que se instancia en distintos roles, como ya hemos señalado arriba. Que agarrar perfile solo un argumento como en el sentido de 'reaccionar' (agarró y dijo); dos argumentos, como en el sentido de 'sorprender' (lo agarró el terremoto); o tres argumentos como en 'sentir' (le agarré cólera a mi esposo) demuestra que el léxico no determina unívocamente las estructuras sintácticas, sino la misma construcción tras categorización.

6. Los hablantes prefieren usar una palabra de sentido material para describir eventos mentales. Pero agarrar aporta matices subjetivos que evidencian modelos cognitivos o marcos culturales adquiridos en la interacción social. Se evidencia que la creatividad de los hablantes depende de la no referencialidad, de la distancia de una teoría de la representación, de la no correspondencia del signo con las cosas. No podemos partir de ideas como sentidos etimológicos en el estudio de la lengua cotidiana, porque esta es ambigua, polisémica y creativa. No representa la realidad, la construye.

7. La reinterpretación sintáctica está motivada por extensiones metafóricas que permiten que las personas se entiendan como objetos y también como lugares; Asimismo, la metonimia reconocida es EL CONTROL FÍSICO POR EL CONTROL DISCURSIVO. Esto significaría que la lengua tiene su propia lógica.

8. El diseño del lenguaje no es tan perfecto como se ha creído siempre ni está predeterminado. La gramática se construye en cada acto de hablar. Los hablantes adquieren constantemente esos patrones o esquemas recurrentes a los que les asignan sentidos y con los que expresan sus subjetividades. Los hablantes producen consciente e inconscientemente construcciones sobre la base cultural que permite entender los mecanismos cognitivos. 


\section{Referencias bibliográficas}

Bybee, J. (2011). Usage-based theory and grammaticalization. En H. Narrog y B. Heine (Eds.), The Oxford Handbook of grammaticalization, pp. 69-78. Nueva York: Universidad de Oxford.

Calsamiglia, H. y Tusón, A. (2001). Las cosas del decir. Manual de análisis del discurso. Barcelona: Ed. Ariel.

Calzado, A. (2015). Las construcciones en la clase de español como lengua extranjera. Marco Ele, Revista de Didáctica ELE. (21)

Company, C. (2004a). ¿Gramaticalización o desgramaticalización? Reanálisis y subjetivización de verbos como marcadores discursivos en la historia del español. En Revista RFE, LXXXIV

Cuenca, M. y Hilferty, J. (1999). Introducción a la lingüística cognitiva. Barcelona: Editorial Ariel.

Garachana, M. y Hilferty, J. (2005). ¿Gramática sin construcciones? Verba, (32), 385-396.

García-Miguel, J. (2005). Aproximación empírica a la interacción de verbos y esquemas construccionales, ejemplificada con los verbos de percepción. ELUA, Estudios de Lingüística, de la Universidad de Alicante, (19),169-191.

Gras, P. (2010). Gramática en interacción: una propuesta desde la gramática de construcciones. En Sueiro, J., Cuevas, M., Dacosta, V., Perez, M. R. (eds.) Lingüística e hispanismo, (pp. 283-298) Lugo: Ed. Axac.

Ignacio, D. (2012). Construcciones de movimiento causado con el verbo poner: un estudio de corpus. Literatura y Lingüística, (27), 137-152.

10. Kleiber, G. (1995). La semántica de los prototipos. Madrid: Visor Libros.

Lakoof, G. y Johnson, M. (2001). Metáforas de la vida cotidiana. Madrid: Cátedra.

Martín, M. (2002) Estudio contrastivo de la metáfora. Tesis de doctorado. Universidad Complutense de Madrid. 
REAL ACADEMIA ESPAÑOLA: Banco de datos (CORDE) [en línea]. Corpus diacrónico del español. <http://www.rae.es> [12/06/16]

Traugott, E. C. (2011). Revisiting subjectification and intersubjectification. De Universidad de Stanford. [Recuperado de http://web.stanford.edu/ traugott/resources/TraugottDavidseIntersbfn.pdf].

Traugott, E. C. (2014). Grammaticalization: an interview with Elizabeth Closs Traugott. ReVEL, 12 (22). [Recuperado de www.revel.inf.br/eng].

Van Dijk, T. (1998). La ciencia del texto. Barcelona: Ed. Paidos.

${ }^{1}$ Adesse (Base de Datos de Verbos, Alternancias de Diátesis y Esquemas Sintáctico-Semánticos del Español) es una base de datos de verbos y construcciones verbales del español que ofrece una caracterización sintáctico-semántica, alternancias de diátesis y frecuencias relativas de cada alternativa construccional para relaciones semánticas similares.

${ }^{2}$ Se encuentra disponible en la siguiente dirección: http://corpus.rae.es/cordenet.html

${ }^{3}$ García-Miguel dirige el proyecto Adesse, del cual hemos tomado como modelo de clasificación de los verbos en macroclases verbales, considerando el significado enciclopédico.

${ }^{4}$ La gramática de construcciones es un modelo de representación del conocimiento gramatical a partir del uso o de la experiencia. Es importante considerar el uso real del lenguaje, ya que las lenguas son instrumentos de interacción social y además porque la significación y las estructuras gramaticales emergen de la experiencia, es decir, del uso contextualizado del lenguaje. 